\title{
Knitting comes of age: the development of a scientific approach to the study of knitwork
}

\author{
Jane Malcolm-Davies $\mathbb{D}$ \\ Centre for Textile Research, University of Copenhagen, Karen Blixens Plads 8, Copenhagen 2300, Denmark \\ jane@jmdandco.com
}

\begin{abstract}
Knitting has received scant attention in the scientific study of textiles despite its continued popularity as a handicraft. As a result, relatively little is published about the evidence for early knitting. It is frequently the victim of mistaken identity: items made by needle binding are often described as knitted; and many more items which are knitted remain unidentified as such. A draft protocol inspired by the Centre International d'Étude des Textiles Anciens' system for the analysis of woven textiles has been developed as part of a project to investigate Knitting in Early Modern Europe (KEME). A lack of unambiguous terminology was also identified as a challenge to the scholarly scrutiny of knitting's origins. The evolution of a protocol and terminology and their application to a collection of knitted caps from the sixteenth century (now published online) is reported here.
\end{abstract}

\section{O tempo do tricot: desenvolvimento de uma abordagem científica para o estudo de malhas}

\section{Resumo}

O trabalho em tricot tem recebido reduzida atenção no que toca ao seu estudo como objecto têxtil, apesar da sua popularidade como trabalho artesanal. Por conseguinte, relativamente pouco tem sido publicado sobre os testemunhos antigos do tricot. $O$ tecido de malha é frequentemente vítima de equívocos: objectos produzidos em binding needle são, por vezes, descritos como malha; outros objectos em malha continuam por ser identificados como tal. Um projecto de protocolo para a análise de tecidos, inspirado no sistema do Centre International d'Étude des Textiles Anciens, foi desenvolvido no contexto do projecto Knitting in Early Modern Europe (KEME). A necessidade de terminologia inequívoca foi identificada neste projecto como um desafio no que toca à análise académica das origens do tricot. $O$ desenvolvimento de um protocolo e de uma terminologia e a sua aplicação no estudo de uma colecção de gorros tricotados do século XVI (disponível online) é apresentado aqui.

\section{Keywords}

Textile analysis

Knit

Cap

Early Modern

Terminology

Database

\section{Palavras-chave}

Análise têxtil

Tricot

Gorro

Idade Moderna

Terminologia

Base de dados 


\section{Introduction}

Knitting is the little sister and poor cousin of textile history. It is a much more recent craft activity than other methods of textile construction such as knotting and weaving, which are millennia older. Despite this relatively short and recent history, knitting has had far fewer resources devoted to its material evidence and historical context than other textile crafts. This is surprising given its continued widespread and growing popularity as a serious leisure pursuit [1]. Ravelry, the premier online hub for knitting enthusiasts, has more than four million members registered on its website. At least 25 of the subgroups within Ravelry pursue an active interest in historical knitting, including the study of sheep and yarn, and how to knit reconstructions of historical objects.

One of the aims of Knitting in Early Modern Europe (KEME), a European Union-funded research project, was to assess how this major gap in the development of textile scholarship might be addressed [2]. A far-flung collection of sixteenth century knitted caps (in museum collections from Copenhagen in the north to Croatia in the south) was the focus of the study. Many of these caps were excavated more than 100 years ago, accessioned with very little information about their archaeological contexts, and then stored with almost no further investigation [3]. KEME's main outcome was the development of an online database intended to showcase the collection as a newly gathered family of objects [4]. The intention was to record their singular and common characteristics to facilitate further study of them as evidence for early modern knitting.

A major challenge to the collection and curatorship of the digital collection was the lack of a conventional way of recording knitted textiles. Previous publications of knitted artefacts offer scant or ambiguous descriptions. Very few provide detailed insight into the materials, construction or current condition of the items - with a few notable exceptions, including one undergraduate thesis [5]. Examples of less than comprehensive reports are: the publication of a significant early 17th century fragment of knitted fabric (see Figure 1), excavated in a latrine in Lüneburg (Germany), which concentrates on a crystalline deposit on the fragment without reporting basic dimensions such as gauge [6]; "fragments of coarse knitting" from the 16th century described as made from plied yarn from a hairy medium fleece from an excavation in Reading (United Kingdom) [7]; and a much-cited source which records 16th century knitted items in the Museum of London collection with the "stitches [wales] per inch" (the horizontal measurement) but not the courses (the vertical measurement) [8].

A necessary requirement of publishing the collection online was a systematic approach to measuring, investigating and recording the material which would facilitate scientific comparison and generate new insights into their historical production. One indication of the urgent need for such a system is the recent publication

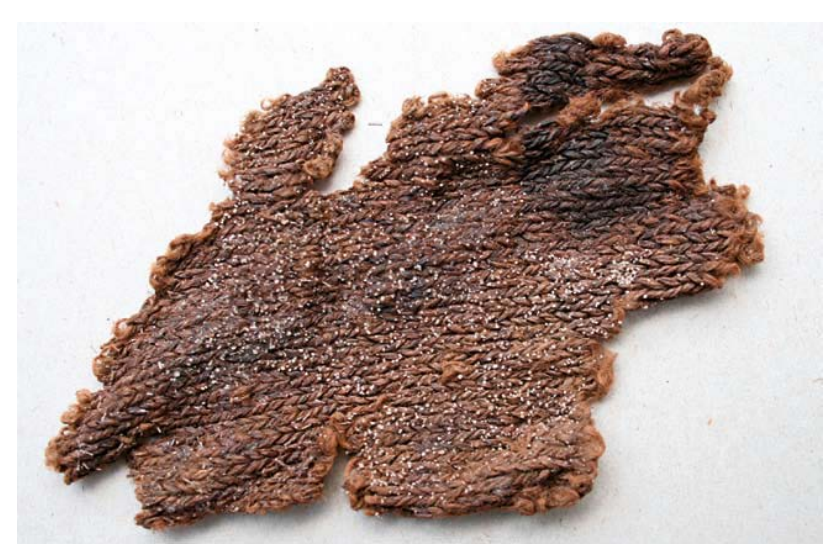

Figure 1. Fragment of knitwork measuring $11.5 \mathrm{~cm} \times 8 \mathrm{~cm}$ from an early 17 th century latrine in Lüneburg, Germany [6]. Image courtesy of Lüneburger Stadtarchäologie.

of archaeological material unconvincingly presented as evidence for Early Bronze Age "two-needle knitting" [9]. This would date knitting's origins to more than five millennia earlier than current scholarly evidence suggests. Methodological flaws, including a failure to define the fabric structure and the terms used to discuss it, contribute to the confused arguments presented.

\section{Literature}

Existing publications which describe knitting in clear terms tend to be manuals on how to do it. Several are exemplary in their use of language despite the difficulties posed by cultural and geographical differences in the way knitting is done and how the processes are named [10-11]. The emphasis in these publications is on communicating methods of knitting not on describing the finished product.

Even the best overviews of knitting history are inconsistent and uncomprehensive in their descriptions of extant artefacts, although the more recent benefits from excellent colour photographs, which are largely lacking from earlier works [12-13]. Some discussions of specific artefacts provide historical context but lack accurate and adequate detailed description [14-15].

Woven textiles may be analysed according to several conventional systems, the most widely accepted of which is published and taught by the Centre International d'Étude des Textiles Anciens (CIETA) in Lyon, France [16]. This served as inspiration for the development of a similar system for knitted objects.

Good practice in terminological work is based on an analysis of the relevant concepts, the identification of appropriate terms to assign to these concepts, and the development of definitions. In this case, there is also a need for the creation of new terms and for translation into other languages [17]. A variety of terms representing the concepts may be synonymous and it is not always necessary to have prescriptive terminology or to outlaw 
previously used terms which convey meanings for specific concepts in other contexts.

Published knitting instructions, for example, serve a different purpose to museum catalogues. Conventions used in instructions rely on a cultural understanding of the practice of knitting and, aside from the language in which the instructions are written, require translation from word to action. Knitters learn that words may need interpretation across geographical and cultural conventions. Their priority is finding the appropriate actions to create/recreate a knitted item.

A new scholarly language for recording the evidence for knitting should be authoritative but need not become the standard in other contexts. The requirement in an academic context is to describe the items accurately in a way that may be understood by scholars. There is no need for words to translate into actions. Indeed, the difference between description and prescription is key. The language used cannot therefore rely on the practical expertise of an experienced knitter or the understanding that words may mean one thing in one place and another elsewhere.

A collaborative team embarked on the task of developing a convention for recording knitted items and a terminology for accurately describing them. The team included textile archaeologists, dress historians, textile terminologists and conservators, as well as knitters - both professionals and hobbyists. The protocol was designed to record the basic details of knitted fragments and the collection of knitted caps under investigation in KEME. Much of the evidence for early knitting is simple in construction and often fragmentary and therefore does not require the complex vocabulary necessary for later evidence. It is anticipated that the protocol and terminology will develop and grow to accommodate more sophisticated knitted items dating from later eras in the future.

\section{Challenges}

Stitch is a problematic word in the description of knitting. It better describes the action rather than the outcome. It is also the word used to describe a sewn stitch and is therefore ambiguous when applied to a knitted fabric, which may carry sewn stitches as seams or embellishment. Loop (a word employed in the modern knitting industry) is a better term for the purpose (see Table 1 for the proposed terminology) [10-11, 18-22]. The loops are usually referred to as knit/plain or purl stitches and are recognised as V-shaped or ridged in appearance. But a right/plain/knit stitch and a left/purl stitch produce exactly the same result - what differs is the loop's relationship to the face of the fabric. It is not possible to say with any certainty which surface of a fabric was facing the knitter when it was under production or which way the knitter was working - from left to right or right to left [23]. Therefore, it is necessary to refer to face loops and reverse loops in the description of the fabric to avoid potentially erroneous assumptions (see below).
Another difficulty presented by fragmentary evidence is that it is not possible to know whether it was produced by knitting round on more than two needles or back and forth on two. The fragment may be the remains of a tube or a flat piece of fabric. Round knitting consists of rounds and back and forth knitting consists of rows. These terms therefore imply the way in which the fabric was constructed and are inadequate for accurate description. The new terminology proposes course (another term used in the modern knitting industry).

One of the other major challenges to the development of a conventional system for recording knitwork was the need to separate assumptions about how an artefact was knitted from a description of what actually remains. Many of the common terms (in English and their equivalents in other languages) imply the method of construction. Stocking stitch, stockinet[te] and jersey, for example, are all terms conventionally used to describe knitted fabric with face loops exclusively on one surface and reverse loops exclusively on the other. Stocking stitch may be produced by employing knit/plain stitches throughout the work when working round or by alternating between plain/knit and purl courses in back and forth knitting. Artefacts with this arrangement of knitted loops is identified as simple knit (see Figure 2 for an Early Modern split-brimmed cap in simple knit $[16,24]$ ) in the proposed terminology, which also includes a new term for what would be called garter stitch in back and forth knitting single ridge knit. Using this term avoids the assumption that an item with this arrangement of loops was necessarily knitted back and forth rather than round [25].

Another challenge is the ambiguity of terms such as right/wrong sides versus right/left sides of the fabric. New terms are proposed for what is designated the side intended to be seen in wear (the recto) and the other side (the verso) [25]. Sometimes, the side intended to be seen may be determined by convention and by reference to contemporary pictorial representations of garments - as,

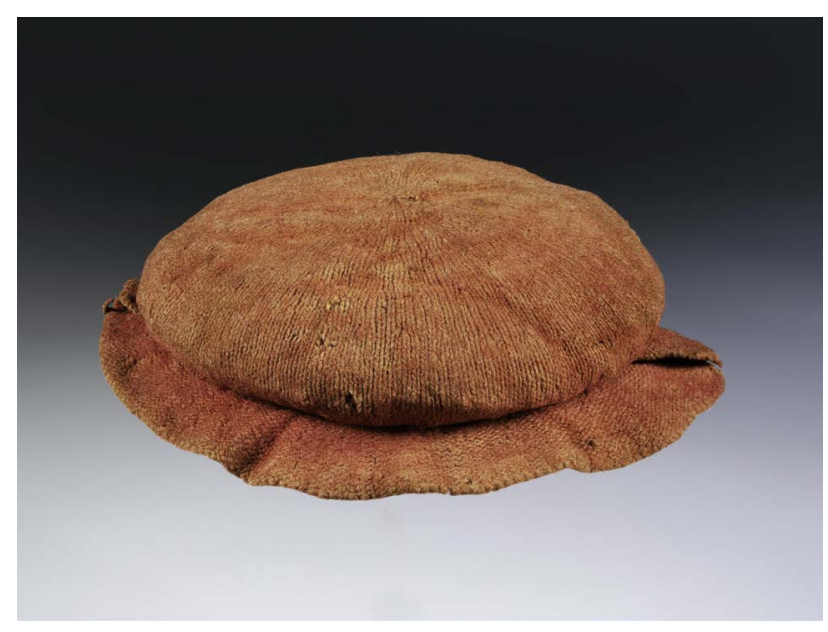

Figure 2. A split-brimmed knitted cap in simple knit fabric at the Victoria \& Albert Museum, London (inventory number 15661901). 
Table 1

Summary of concepts and proposed key terms for reporting archaeological and historical knitwork [10-11, 18, 20-22]

\begin{tabular}{|c|c|c|c|}
\hline Concept & & Discussion points, variables, references & Proposed term (English) \\
\hline \multirow[t]{3}{*}{ Tool } & \multirow[t]{3}{*}{ Needles (two or more than two) } & Sticks, pricks, wires, pins & Needles (plural) \\
\hline & & Double-pointed & \\
\hline & & Single-pointed & \\
\hline \multirow[t]{3}{*}{ Material } & Yarn & Applies to all fibres [20, p. 10] & Yarn \\
\hline & Fibre & $\begin{array}{l}\text { Animal, plant, mineral or synthetic [20, } \\
\text { pp. 4-5] }\end{array}$ & Fibre \\
\hline & Fibre or yarn as structural element & Element [20, p.8] & Element \\
\hline \multirow{9}{*}{$\begin{array}{l}\text { Element } \\
\text { structure }\end{array}$} & Single (spun or not spun) & {$[20, p .8]$} & Single \\
\hline & Spin/twist direction & {$[20$, p.11] } & $\begin{array}{l}\text { Spin (S, Z) for single yarn; } \\
\text { twist for plied }\end{array}$ \\
\hline & Spin/twist angle (degrees from vertical) & {$[20, \mathrm{p} .11]$} & $\begin{array}{l}\text { Spin angle for single yarn; } \\
\text { twist angle for plied }\end{array}$ \\
\hline & $\begin{array}{l}\text { More than one (spun or not spun) combined } \\
\text { or plied }\end{array}$ & {$[20, p .8]$} & Compound \\
\hline & $\begin{array}{l}\text { Compound (spun or not spun) but not } \\
\text { twisted together }\end{array}$ & {$[20, p .8]$} & Combined (I) \\
\hline & Compound and twisted together & {$[20, \mathrm{p} .10]$} & Plied (S, Z) \\
\hline & Ply & {$[20$, p.10] } & Ply \\
\hline & Number of single yarns & {$[20$, p.11] } & 2- ply, 3-ply etc \\
\hline & Additional twist & Re-plied [20, p. 11]/cabled [21] & Cabled \\
\hline \multirow{2}{*}{$\begin{array}{l}\text { Method of } \\
\text { working }\end{array}$} & In a continuous spiral & Knitted in rounds & Round \\
\hline & $\begin{array}{l}\text { Back and forth in the same plane - } \\
\text { including turned/not turned }\end{array}$ & Straight rows [22] & Back and forth \\
\hline Form & Form of item & $\begin{array}{l}\text { Tubular, conical, discoid, "square, rectangu- } \\
\text { lar, or otherwise shaped" }[20, \text { p. 30] }\end{array}$ & As appropriate \\
\hline Orientation & Top/bottom & & Top/bottom \\
\hline \multirow{10}{*}{$\begin{array}{l}\text { Fabric } \\
\text { features }\end{array}$} & Starting edge & Casting on or binding on $[10$, p. 656$]$ & Cast-on edge \\
\hline & Finishing (locking) edge & Casting offf or binding off $[10$, p. 656$]$ & Cast-off edge \\
\hline & Unfinished edge & Cut/torn/decayed & Edge \\
\hline & Turning edge & Secure edge $[18$, p. 3.3 .2$]$ & Selvedge \\
\hline & Loop & Stitch & Loop \\
\hline & Column/s of vertically aligned loops & & Wale/s \\
\hline & $\begin{array}{l}\text { Course/s of element through horizontally } \\
\text { aligned loops }\end{array}$ & & Course/s \\
\hline & \multirow[t]{3}{*}{ Gauge (US)/Tension (UK) } & & Gauge \\
\hline & & $\begin{array}{l}\text { Wales } \times \text { courses per } 10 \mathrm{~cm} \text { square or } \\
\text { inch square }\end{array}$ & Loop density \\
\hline & & $\begin{array}{l}(\mathrm{W} \text { per } \mathrm{cm} \times \mathrm{YD})+(\mathrm{C} \text { per } \mathrm{cm} \times \mathrm{YD}) \\
\text { minus }(\mathrm{W} \text { per } \mathrm{cm} \times \mathrm{YD}) \times(\mathrm{C} \text { per } \mathrm{cm} \times \\
\mathrm{YD}) \text {, where } \mathrm{W} \text { is wales, } \mathrm{C} \text { is courses and } \\
\mathrm{YD} \text { is yarn diameter }\end{array}$ & Cover factor \\
\hline
\end{tabular}




\section{Table 1 (continued)}

\begin{tabular}{|c|c|c|c|}
\hline Concept & & Discussion points, variables, references & Proposed term (English) \\
\hline \multirow{9}{*}{$\begin{array}{l}\text { Fabric } \\
\text { features }\end{array}$} & Surface of fabric & Right/wrong sides & Recto/verso \\
\hline & Surface of item & Inside/outside & Inside/outside \\
\hline & Flat side or worked loop & Right/knit/plain stitch in fabric & Face loop \\
\hline & Ridge side or worked loop & Left/purl stitch in fabric & Reverse loop \\
\hline & \multirow[t]{2}{*}{ Shaping } & Addition of wale/s & Increase (noun) \\
\hline & & Removal of wale/s & Decrease (noun) \\
\hline & Start/finish of round & Step/jog [10, p. 32; 11, p. 31] & Jog \\
\hline & $\begin{array}{l}\text { Decoration worked as part of fabric } \\
\text { structure, whether loop formation or colour } \\
\text { changes }\end{array}$ & $\begin{array}{l}\text { Stitch patterns [11, p. 19]; decorative } \\
\text { stitch technique }[10, \text { p. } 660]\end{array}$ & Stitch/colour pattern \\
\hline & Decoration applied to the fabric & Ornamentation & Embellishment \\
\hline \multirow{6}{*}{$\begin{array}{l}\text { Fabric } \\
\text { structure } \\
\text { (as } \\
\text { observed) }\end{array}$} & $\begin{array}{l}\text { One surface exclusively of face and the other } \\
\text { exclusively of reverse loops }\end{array}$ & Plain/Stockinet[te]/Jersey & Simple knit fabric \\
\hline & $\begin{array}{l}\text { Two surfaces each of alternate courses of } \\
\text { face and reverse loops }\end{array}$ & Garter stitch & Single ridge knit fabric \\
\hline & Enumerated courses of face/reverse loops & & Ridge fabric \\
\hline & $\begin{array}{l}\text { Two surfaces of alternate wales of face and } \\
\text { reverse loops }\end{array}$ & Single rib & Single rib fabric \\
\hline & Enumerated wales of face/reverse loops & & Rib fabric \\
\hline & $\begin{array}{l}\text { Fabric made with two elements of the same } \\
\text { yarn in various configurations, one working } \\
\text { and one carried across either surface of fabric }\end{array}$ & & Twined knit \\
\hline \multirow[t]{4}{*}{ Finish } & & & Matted \\
\hline & & & Fulled \\
\hline & & & Napped \\
\hline & & & Shorn \\
\hline \multirow[t]{2}{*}{ Colour } & & & Pigmented \\
\hline & & & Dyed \\
\hline $\begin{array}{l}\text { Process/ } \\
\text { action }\end{array}$ & Construction of fabric & Knit & Work \\
\hline Descriptor & & & Knitted \\
\hline Product & & Under construction/finished & Knitwork \\
\hline
\end{tabular}

for example, with a stocking or a fragment of one. One surface consists entirely of face loops and consequently the other surface is of reverse loops. Usually, knitted legwear is worn with the face loops on the outside and the reverse loops on the inside (see Figure 3 for the recto and verso of an 18th century stocking). Thus, the surface of face loops is the recto and the surface of reverse loops is the verso. It is much more difficult to designate recto/verso when fragments are less obviously part of a garment. In these cases, it is recommended that one surface be designated the recto in order to make further description feasible.

Other essential descriptions for understanding a knitted fabric include the number of loops in both the horizontal and vertical directions. These are recorded according to the protocol as courses per $10 \mathrm{~cm}$ (or inch) and wales per $10 \mathrm{~cm}$ (or inch), respectively, in the same way as the gauge of knitted fabric is recorded industrially. These measurements permit further useful ratios, such as the fabric's density and cover factor, to be calculated, 


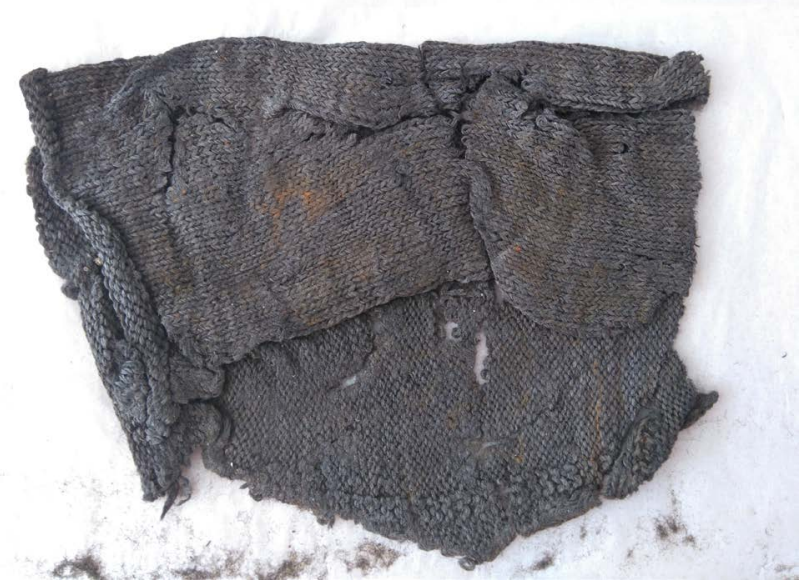

Figure 3. Fragment of a knitted stocking dated 1690 to 1770 excavated at Maersks Hovedsaede, Esplanaden, Copenhagen (KBM 2307), showing recto (surface with v-shaped loops worn on the outside) and verso (surface with ridge-shaped loops worn on the inside). thereby permitting comparisons between different knitted items.

\section{Application of the protocol}

The development of the online database of knitted caps preceded the detailed terminological work and therefore does not demonstrate its application in full. It does, however, record all the recommended basic dimensions with the gauge and yarn diameter for each cap. There are also photographs and microscope images providing information indicative of the fabric's characteristics, which, in most cases is simple knit throughout (see Figure 4 for an example of a database entry for a 16th-century knitted cap lining).

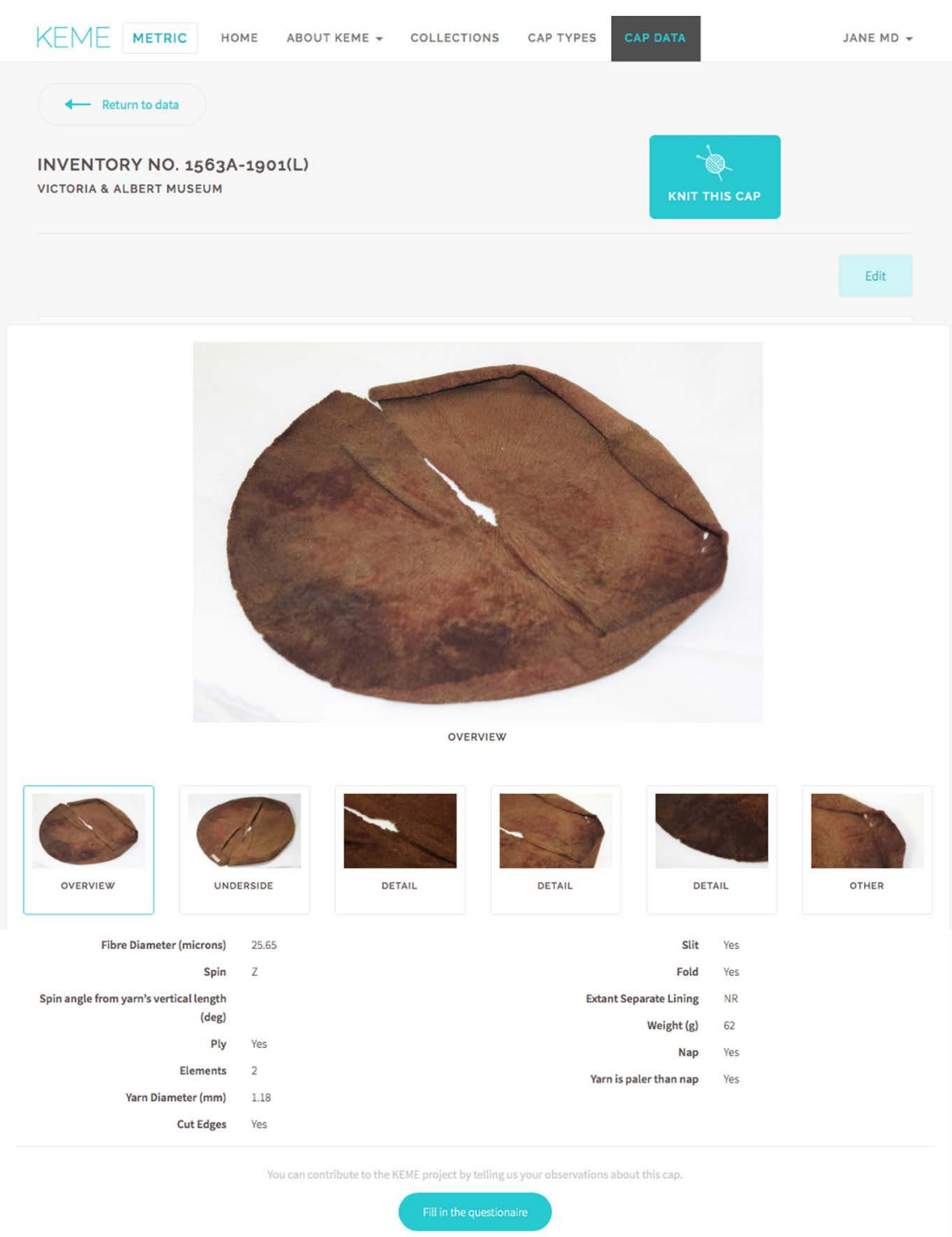

Figure 4. KEME database entry for a knitted cap lining at the Victoria \& Albert Museum, London (inventory number 1563-1901) showing fibre diameter based on scanning electron microscope measurements (average of 100) and yarn diameter based on Dino-Lite USB microscope measurements (average of 10). Photograph by Jane Malcolm-Davies; image courtesy of the V\&A Museum. 


\section{Table 2}

Proposed dossier de recensement or protocol for recording archaeological and historical knitwork [16, 24]

Allow two to three hours for a thorough examination and detailed recording.

Work in metric or imperial measurements throughout.

Note whether measurements are approximate or precise.

Item identification

Location where the item is currently held

Inventory/accession number

Object name (in official record)

Source/find location (if known)

Provenance (if known)

$2 \quad$ Item material \& yarn structure

Details of each yarn, including those in structure and sewing or embellishment, as follows:

Fibre: animal, plant, mineral, synthetic (wool, silk, linen, cotton, metal, acrylic etc)

Fibre diameter (in microns based on 100 measurements, if possible)

Yarn diameter based on at least 10 measures with range stated

Yarn analysis, as follows:

Single or compound elements

If compound, combined, plied or cabled

If compound, number of single component yarns

For each yarn:

Single yarn diameter/s based on at least 10 measures with range stated

Single yarn spin (Z, S, I) “I” indicates no visible spin

Single yarn spin angle/s (0-45 degrees) based on at least 10 measures with range stated

Plied yarn diameter/s based on at least 10 measures with range stated

Ply twist/s (Z, S, I)

Ply angle/s (0-45 degrees) based on at least 10 measures with range stated

If cabled, number of plied yarns, twist \& twist angle based on at least 10 measures with range stated

One yarn:

Simple knit (yes/no)

Single ridge (yes/no)

Ridge knit (with enumerated courses of face/reverse loops)

Single rib (yes/no)

Rib fabric (with enumerated wales of face/reverse loops)

Other combination of face and reverse loops (with chart/diagram, as necessary)

More complex structures (with chart/diagram, as necessary)

More than one yarn:

Twined knit (yes/no) 


\section{Table 2 (continued)}

Surface designated recto with reason (with chart/diagram as necessary)

Surface designated verso with reason (with chart/diagram as necessary)

Designated working direction with reason

Loop height (average based on a minimum of 10 loops)

Loop width (average based on a minimum of 10 loops)

Gauge: count wales and courses, as follows:

Wales (count horizontally) per $10 \mathrm{~cm}$ or inch

Courses (count vertically) per $10 \mathrm{~cm}$ or inch

Course to wale ratio $=$ course count divided by wale count expressed as n: 1

Loop density $=$ wales $\mathrm{x}$ courses per $10 \mathrm{~cm}$ square or inch square

Cover factor $=(\mathrm{W}$ per $\mathrm{cm} \times \mathrm{YD})+(\mathrm{C}$ per $\mathrm{cm} \times \mathrm{yd})$ minus $(\mathrm{W}$ per $\mathrm{cm} \times \mathrm{YD}) \mathrm{x}(\mathrm{C}$ per $\mathrm{cm} \times \mathrm{YD}) \mathrm{W}$ refers to wales, $\mathrm{C}$ to courses and YD to yarn diameter.

Cast-on edges (yes/no \& description)

Cast-off edges (yes/no \& description)

Selvedges

Cut edges (yes/no \& description)

Torn edges (yes/no \& description)

Decayed edges (yes/no \& description)

Shaping: number of increases (locations \& type/s - cite evidence in full)

Shaping: number of decreases (locations \& type/s - cite evidence in full)

Embellishment

Item form \& construction

Form/s: Tube - (two edges, two surfaces) or plane (one edge, two surfaces)

Shape/s (disc, square, rectangle, triangle, otherwise etc) with diagram, as necessary

Designated top/bottom with reason

Dimensions of item (with diagram, as necessary), as follows:

Length (maximum/minimum, if appropriate)

Width (maximum/minimum, if appropriate)

Depth (maximum/minimum, if appropriate)

Designated inside

Designated outside

Weight (grams or ounces)

A pilot database was published online in May 2018 with invitations issued to a citizen science team of volunteers (the KEME Team) to visit and comment on the material via a linked questionnaire. The purpose of recruiting a team was to track the usefulness of the protocol in making detailed information available to an identified user group, the members of which are now helping to refine it. The database was updated in August 2018 to include 68 of the $100+$ knitted caps included in the KEME project.

The 168 volunteers who signed up to participate in experimental archaeology as well as online activities were among the first adopters of the database, although the invitation brought many more visitors in the first six 


\section{Table 2 (continued)}

$6 \quad$ General overview

Finish: Matted (yes/no)

Finish: Evidence of fulling, napping, shearing (yes/no \& description of evidence)

Colour/s: Archaeological brown - yes/no (light, dark, further details)

Colour/s: Munsell, CIELAB or a similar colour recording system definition

Natural pigmentation (yes/no \& description)

Dyed (yes/no \& description)

Sewn seams, fastenings, evidence of wear or use, damage, repairs, mistakes/anomalies, marking, additions, writing, evidence of conservation work

Further observations (including number of parts, pattern sections, shaping, seams, hems, gussets, neckband, finishes)

Drawing/s completed (yes/no)

Photographs taken (yes/no)

Interpretation

Deductions as to the technique/s used to make the fabric with appropriate evidence, as follows:

Hand/machine/indeterminate

Round

Back and forth (turned/unturned)

Working direction (with evidence from cast on, cast off, increases, decreases)

Fleece characteristics: modern fine fleece is usually interpreted as less than $20.6 \mu \mathrm{m}$, medium from 22 to $29.3 \mu \mathrm{m}$, coarse from 31 to $34.4 \mu \mathrm{m}$ and very coarse more than $36 \mu \mathrm{m}$

$8 \quad$ Further information

Object description (in official record): take photocopy, photograph or pdf, if possible

Comparable items (locations and accession numbers)

Relevant literature (full references)

$9 \quad$ Examination record

Name of examiner (first name \& surname, affiliation with contact details)

Place of examination

Date of report

months. There were 339 visitors to the database of whom 91 were lurkers (people who check in regularly but do not interact online with the material). A hard core of 10 engagers took the time to examine caps in detail and comment on them [26-27].

The second largest group of KEME Team volunteers (20 per cent) identified themselves as reenactors, who were interested in knitting reconstructions [27]. The database includes a feature called "Knit this cap" which quickly retrieves the most necessary information for reconstructing it - the gauge and yarn diameter.
The largest numbers of KEME Team volunteers are in the United States (48 per cent) and the United Kingdom (27 per cent), where imperial measurements are used more readily than metric measurements. The database offers a feature which allows users to toggle between these two systems, thereby making the material more accessible and comprehensible [27].

The draft protocol has also been applied to other early modern artefacts, including fragments, caps, stockings and mittens, most of which are previously unpublished. The reports provide comparable data across 
all the evidence offering a previously impossible scientific overview of evidence for early modern knitting [28-33].

\section{Conclusion}

This paper serves to introduce the draft protocol (see Table 2) and encourage its use in cataloguing and the study of knitted items. The use of a conventional system will also facilitate the entry of further knitted artefacts into the online database at http://www.kemeresearch. com, which has gathered much of the evidence for early modern knitting into an easily accessible public collection (see Figure 5 for the website hosting the database).

Feedback on the protocol's application to more complex items, such as liturgical gloves and patterned garments, is welcomed. Further collaboration on how the protocol can be translated into other languages is also an ongoing part of the project.
KEME has generated the possibility for mute objects lying in the dark drawers of museum storage to generate new scholarship through the application of a protocol for scientific study.

\section{Acknowledgements}

Many thanks to Ruth Gilbert, who has collaborated on this project throughout, and to Susanne Lervad for guidance on good practice in terminology work. The project was made possible through an EU-funded Marie Sklodowska Curie Fellowship 2015 to 2017 (grant agreement number 656748).

\section{ORCID}

Jane Malcolm-Davies

(iD) https://orcid.org/0000-0001-7765-0712

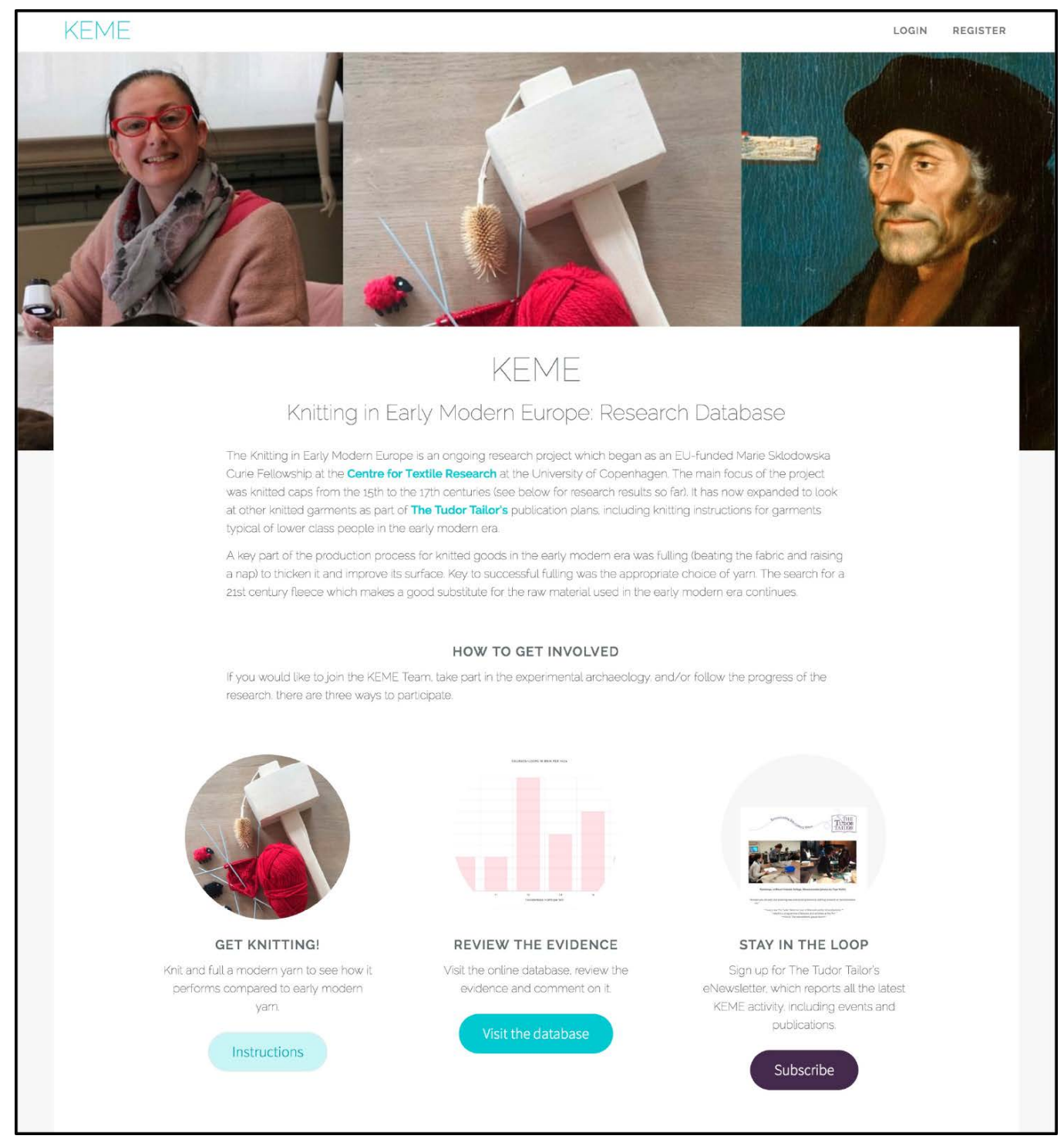

Figure 5. The home page for the Knitting in Early Modern Europe website and database at http://www.kemeresearch.com. 


\section{References}

1 Orton-Johnson, K., 'Knit, purl and upload: new technologies, digital mediations and the experience of leisure', Leisure Studies 33(3), (2014) 305-321, https://doi.org/10.1080/026143 67.2012.723730.

2 Malcolm-Davies, J., 'Project homepage and database', in Knitting in Early Modern Europe (KEME), https:// kemeresearch.com/home (accessed 2018-7-27).

3 Malcolm-Davies, J.; Davidson, H., "“He is of no account ... if he have not a velvet or taffeta hat': a survey of 16th century knitted caps", in Aspects of the Design, Production and Use of Textiles and Clothing from the Bronze Age to the Early Modern Era, ed. K. Grömer \& F. Pritchard, Archaeolingua, Budapest (2015) 223-232.

4 Kopytoff, I., 'The cultural biography of things: commoditisation as process', in The Social Life of Things, ed. A. Appadurai, University Press Cambridge, Cambridge (1986) 64-91, https://doi.org/10.1017/CBO9780511819582.004.

5 Botticello, J., 'The conservation of two Tudor knitted woollen flat caps', undergraduate thesis, Camberwell College, London (2003).

6 Haase, W.; Weißgraf, T., 'Ausblühungen an Gestricken des 17. Jahrhunderts aus einer Kloake in Lüneburg', in Denkmalpflege in Lüneburg, Lüneburger Stadtarchäologie, Lüneburg (2007) 75-79.

7 Rogers, P. W., 'Textiles', in Under the Oracle. Excavations at the Oracle Shopping Centre Site 1996-8: The Medieval and Post-Medieval Urban Development of the Kennet Floodplain in Reading, ed. B. Ford, D. Poore, R. Shaffrey \& D. Wilkinson, Oxford Archaeology, Oxford (2013) 197-198.

8 Green, E., 'Is Tudor London trendy? Tudor textiles from London: cloth, clothing and status', undergraduate thesis, Bradford University, Bradford (2001).

9 Sagona, C., 'Two-needle knitting and cross-knit looping: Early Bronze Age pottery imprints from Anatolia and the Caucasus', Oxford Journal of Archaeology 37(3) (2018) 283297, https://doi.org/10.1111/ojoa.12141.

10 Hiatt, J. H., The Principles of Knitting: Methods and Techniques of Hand Knitting, Touchstone, New York (2012)

11 Stanley, M., Knitter's Handbook: A Comprehensive Guide to the Principles and Techniques of Handknitting, David \& Charles, Newton Abbot (2001).

12 Rutt, R., A History of Hand Knitting, reprinted, Interweave Press, Loveland (1987).

13 Black, S., Knitting: Fashion, Industry, Craft, V\&A Publishing, London (2012).

14 Buckland, K., 'The Monmouth cap', Costume 13 (1979) 23-37, https://doi.org/10.1179/cos.1979.13.1.23.

15 Ringgaard, M., 'The knitted sugar-loaf hat', in Fashioning the Early Modern: Dress, Textiles and Innovation in Europe 1500-1800, ed. E. Welch, Pasold Research Fund \& Oxford University Press, Oxford (2017) 313-316.

16 Vocabulary of Technical Terms: Fabrics, Centre International d'Étude des Textiles Anciens, Lyon (2006).

17 Dury, P.; Lervad, S. 'Synonymic variation in the field of textile terminology, in Textile Terminologies in the Ancient Near East and Mediterranean from the Third to the First Millenia, ed. C. Michel. \& M.-L. Nosch, Oxbow Books, Oxford (2016) 1-9.

18 ISO 4921:2000 Knitting Basic Concepts and Vocabulary, International Organization for Standardization, https:// www.iso.org/obp/ui/\#iso:std:iso:4921:ed-2:v1:en (accessed 2018-7-27)

19 ISO 8388:1998 Knitted Fabrics, International Organization for Standardization, https://www.iso.org/obp/ ui/\#iso:std:iso:8388:ed-1:v1:en (accessed 2018-7-27).

20 Emery, I., The Primary Structure of Fabrics: An Illustrated Classification, Thames \& Hudson, London (1994).

21 Walton, P.; Eastwood, G., A Brief Guide to the Cataloguing of Archaeological Textiles, 4th ed., Textile Research Associates, York (1988).

22 Phipps, E., Looking at Textiles: A Guide to Technical Terms, J. Getty Trust Publications, Los Angeles (2011).

23 Thomas, M., Mary Thomas's Book of Knitting Patterns, Hodder \& Stoughton, London (1943).

24 Gilbert, R., 'The king's vest and the seaman's gansey: continuity and diversity of construction in hand-knitted body garments in north western Europe since 1550', MPhil thesis, Textile Conservation Centre, University of Southampton, United Kingdom (2009).

25 Malcolm-Davies, J.; Gilbert, R.; Lervad, S., 'Unravelling the confusions: Defining concepts to record archaeological and historical evidence for knitting', Archaeological Textiles Review 60 (2018) 10-24.

26 Sun, N.; Pei-Luen, R.; Ma, L., 'Understanding lurkers in online communities', Computers in Human Behavior $\mathbf{3 8}$ (2014) 110-117, http://dx.doi.org/10.1016/j.chb.2014.05.022.

27 Malcolm-Davies, J., 'Knitting virtual tribes together: new audiences for cultural objects', in Florence Heri-Tech - The Future of Heritage Science and Technologies, ed. R. Furferi, R. Giorgi, L. Governi, M. Matteini \& Y. Volpe, IOP Publishing (2018), https://doi.org/10.1088/1757-899X/364/1/012031.

28 Gilbert, R., 'Do you read my signal? An attempt at the application of clear terminology in recording archaeological knitwork', Archaeological Textiles Review 60 (2018) 25-33.

29 Ringgaard, M., 'The church cap and the crypt cap: Early Modern knitted fragments found in Denmark', Archaeological Textiles Review 60 (2018) 34-41.

30 O'Connell Edwards, L., 'Knitted wool stockings in the Museum of London: A study of 16th century construction', Archaeological Textiles Review 60 (2018) 42-51.

31 Odstrčilová, S., 'Early Modern stockings in museums in the Czech Republic', Archaeological Textiles Review 60 (2018) 5163.

32 Lundin. H., 'Knitted fragments of clothes excavated from the Swedish 17th century flagship Kronan', Archaeological Textiles Review 60 (2018) 64-74.

33 Willemsen, A., 'Two knitted mittens from a 17th century Dutch shipwreck', Archaeological Textiles Review 60 (2018) 75-82.

Received: 2018-7-31

Revised: 2018-12-19

Accepted: 2019-1-15

Online: 2019-2-25

This work is licensed under the Creative Commons Attribution-NonCommercial-NoDerivatives 4.0 International License. To view a copy of this license, visit http://creativecommons.org/licenses/by-nc-nd/4.0/deed.en. 